\title{
On the accuracy of analysed low temperatures in the stratosphere
}

\author{
B. M. Knudsen \\ Danish Meteorological Institute, Lyngbyvej 100, 2100 Copenhagen, Denmark \\ Received: 20 June 2003 - Published in Atmos. Chem. Phys. Discuss.: 11 August 2003 \\ Revised: 8 October 2003 - Accepted: 10 October 2003 - Published: 16 October 2003
}

\begin{abstract}
The accuracy of ECMWF (European Centre for Medium-Range Weather Forecasts) temperatures has been investigated by comparison to radiosonde temperatures. Particularly, the extent of temperatures below which Polar Stratospheric Clouds (PSCs) consisting of nitric acid trihydrate can exist $\left(\mathrm{T}_{\mathrm{NAT}}\right.$ ) has been studied. In the 1999/2000 winter analyses and in the 40 year reanalyses (ERA40) from the winter 1996/1997 the analysed extent agrees quite well with the radiosondes extent, whereas the 2002/2003 winter analyses considerably overestimate the extent from 40 $11 \mathrm{hPa}$ due to a general cold bias. Close to the frost point small-scale temperature variations, which ECMWF does not catch, substantially increase the extent of these low temperatures. Some of these small-scale variations are caused by lee-waves.
\end{abstract}

\section{Introduction}

Temperatures are important in many aspects of atmospheric research and many studies have investigated the accuracy of analysed temperatures (e.g. Hertzog et al., 2003, Pommerau et al., 2002, Knudsen et al., 2002, and references therein). Ozone depletion in the Polar Regions is enhanced, when PSCs form at low temperatures. Therefore, a particular interest has been the accuracy of such low temperatures. Knudsen (1996) and Manney et al. (1996) compared various analyses to radiosonde temperatures and found substantial warm biases of the analyses. Pullen and Jones (1997) compared UK Meteorological Office (MO) analyses to partially independent ozonesondes and also found a warm bias. Davies et al. (2002) showed good agreement between radiosondes and ECMWF at low temperatures and poor agreement with MO due to erroneous ozone concentrations in the model cli-

Correspondence to: B. M. Knudsen

(bk@dmi.dk) matology in the winter 1999/2000 (Manney et al., 2003). Manney et al. (2003) intercompared the PSC areas calculated from various analyses and found substantial differences. The present study updates these findings to the latest ECMWF analyses and the ERA40 reanalyses and presents some new insights concerning the role of small-scale temperature variations.

\section{Data}

\subsection{ECMWF analyses}

In the winter 1999/2000 ECMWF used a T319 spherical harmonical model, with 60 vertical levels up to $0.1 \mathrm{hPa}$. The spacing in the stratosphere is $1.5 \mathrm{~km}$ (Simmons et al., 1999) (levels used here are at or near 10, 12, 15, 19, 23, 29, 36, $44,55,67,80,96$, and $113 \mathrm{hPa}$ ). A 4-D variational assimilation scheme (Rabier et al., 2000) is used. The analyses are extracted from T106 truncated spherical harmonical fields. In the winter 2002/2003 ECMWF used a T511 truncation. On 22 January 2002, ECMWF introduced model changes concerning the assimilation of high resolution Advanced Microwave Sounding Unit (AMSU) data, which significantly increased the number of data in the Arctic.

In the winter 1996/1997 the ECMWF 40 year reanalyses (Simmons and Gibson, 2000) are used. They are produced with a T159 model using a 3-D variational assimilation. On 1 January 1997, the assimilation was changed, so to avoid spinup effects the first 7 days of January were omitted. The late start this winter has no practical implications because no temperatures below $\mathrm{T}_{\mathrm{NAT}}$ were observed in the first part of the winter. The reanalysis in the winter 1995/96 has been used in one figure due to its large extent of frost point temperatures, which improve the statistics. The temperature accuracy in the winter $1995 / 1996$ is not significantly different from the winter 1996/1997, except below $61 \mathrm{hPa}$ where unusually low 
Table 1. $\mathrm{T}_{\mathrm{NAT}}, \mathrm{T}_{\mathrm{ICE}}, \mathrm{HNO}_{3}$ and $\mathrm{H}_{2} \mathrm{O}$ mixing ratios used

\begin{tabular}{lcccc}
\hline Layer $(\mathrm{hPa})$ & $105-61$ & $61-40$ & $40-26$ & $26-11$ \\
\hline $\mathrm{T}_{\mathrm{NAT}}(\mathrm{K})$ & 197.4 & 195.2 & 193.6 & 190.9 \\
$\mathrm{~T}_{\mathrm{ICE}}(\mathrm{K})$ & 190.8 & 187.9 & 186.1 & 183.8 \\
$\mathrm{HNO}_{3}$ (ppbv) & 6.3 & 9.0 & 10.2 & 8.9 \\
$\mathrm{H}_{2} \mathrm{O}$ (ppmv) & 4.5 & 4.6 & 5.2 & 6.1 \\
\hline
\end{tabular}

ozone mixing ratios may have caused a cooling. The period 14-21 December 1995 is omitted due to excessive errors caused by almost no radiosondes reaching $30 \mathrm{hPa}$ in the Arctic.

\subsection{Radiosondes}

In this study November-March radiosondes from $50^{\circ}-90^{\circ} \mathrm{N}$, and $140^{\circ} \mathrm{W}-140^{\circ} \mathrm{E}$ are used, because this is where most PSC's occur (Pawson et al., 1995). Only 0 and 12:00 UT sondes are used. Radiosonde temperatures are reported on standard levels, of which 10, 20, 30, 50, 70, 100, and $150 \mathrm{hPa}$ are used here together with significant levels in between. The sondes have been taken from the ECMWF GTS archives, and only the uncorrected data are used. For consistency primarily Vaisala radiosondes have been used, although the Russian sondes perform very well at night (Luers and Eskeridge, 1998). Mainly sondes inside the polar vortex, defined as where MPV (modified potential vorticity referenced to $475 \mathrm{~K}$; Lait, 1994) is larger than $35 \times 10^{-6} \mathrm{~K} \mathrm{~m}^{2} \mathrm{~s}^{-1} \mathrm{~kg}^{-1}$, have been used. The Vaisala radiosondes have a reproducibility of $0.2 \mathrm{~K}$ and small IR/solar radiation corrections. According to WMO (1998), the Canadian sondes used the radiation correction V93 and most other stations with Vaisala sondes used the V86 correction by the beginning of 1998. The V86 correction leads to approximately $0.3 \mathrm{~K}$ higher temperatures at $30 \mathrm{hPa}(0.7 \mathrm{~K}$ at $10 \mathrm{hPa})$ during night.

In the winter 2002/2003 the Vaisala radiosonde type RS90 was used occasionally by several European and Greenland stations. Its temperature sensor has a much faster response than the one used in the RS80 radiosonde, which could lead to differences in the temperature measured, when there is a vertical gradient in the temperature.

\subsection{Filtering out atmospheric waves}

Atmospheric waves have a great influence on stratospheric temperatures. To determine the amount of wave activity the procedure by Whiteway (1999) has been adopted. Therefore, the temperature perturbations from a background state (a cubic polynomial fit to the radiosonde temperature profile) were calculated. The perturbation potential energy density, $E_{p}$, was determined as the variance of fractional perturbation multiplied by $1 / 2(\mathrm{~g} / \mathrm{N})^{2}$, where $\mathrm{g}$ is the acceleration of gravity and $\mathrm{N}$ is the buoyancy frequency (Whiteway,
1999). $E_{p}$ was calculated in the pressure range $150-50 \mathrm{hPa}$ $(12-19 \mathrm{~km})$, whereas Whiteway (1999) used $11-18 \mathrm{~km}$. The amount of wave activity was then classified in the following way:

$E_{p}<1 \mathrm{~J} / \mathrm{kg}$ : inhibited wave activity

$E_{p}>2 \mathrm{~J} / \mathrm{kg}$ : enhanced wave activity

This procedure does not work for waves with wavelengths longer than $7 \mathrm{~km}$ in the vertical, but such long waves would usually be accompanied by waves of shorter wavelengths (e.g. Dörnbrack et al., 2002), because the mountains themselves usually have structures on a broad range of scales. However, a few strong lee-wave events with long wavelengths and temperatures close to the frost point have been re-classified as enhanced wave activity. The vertical resolution at ECMWF is $1.5 \mathrm{~km}$, so waves with wavelengths shorter than $3 \mathrm{~km}$ cannot possibly be resolved. In most of this study only data with inhibited wave activity have been used.

\section{Results}

The ECMWF temperatures are an average over a whole model layer. Therefore the radiosonde temperatures have been averaged over the same layers for the comparison. Figure 1 shows the distribution of temperature biases between radiosonde and ECMWF temperatures $\left(\mathrm{T}_{\mathrm{OBS}}-\mathrm{T}_{\mathrm{ECM}}\right)$ around $30 \mathrm{hPa}(40-26 \mathrm{hPa})$ for the winter $1999 / 2000$. To avoid the influence of e.g. occasional errors in the radiosonde data, temperatures more then $20 \mathrm{~K}$ away from the ECMWF temperatures have been disregarded. Further the median temperature bias is used instead of the mean and the $68 \%$ fractile of the absolute temperature bias is used instead of the standard deviation. The distributions are compared to Gaussian distributions with the median as mean and $68 \%$ fractile as standard deviation. It is evident that the observed distribution has much larger wings than the Gaussian distribution. A chi-square test shows that the difference between the distributions is highly significant. Temperature differences above $2 \mathrm{~K}$ occur in about $3 \%$ more of the observations than for the Gaussian distribution for inhibited wave activity. Not surprisingly it occurs more often for enhanced activity (about $4 \%)$ and the $68 \%$ fractile is also larger $(0.87 \mathrm{~K}$ compared to $0.81 \mathrm{~K}$ ). Below $\mathrm{T}_{\mathrm{NAT}}$ the $68 \%$ fractiles become larger and most of the outliers occur here. $\mathrm{T}_{\mathrm{NAT}}$ is calculated by assuming a LIMS January $76^{\circ} \mathrm{N}$ profile of nitric acid and water vapour is assumed to be $4.5 \mathrm{ppmv}$ below $450 \mathrm{~K}, 6.5 \mathrm{ppmv}$ above $650 \mathrm{~K}$, and to vary linearly in between (Buss, 2003; Schiller et al., 2002; and references therein). The temperature thresholds $\mathrm{T}_{\mathrm{NAT}}$ and $\mathrm{T}_{\mathrm{ICE}}$ as well as the concurrent $\mathrm{HNO}_{3}$ and $\mathrm{H}_{2} \mathrm{O}$ mixing ratios are shown for the mid points of the four layers used in this study in Table 1 . 
In Table 2 the median biases $\left(\mathrm{T}_{\mathrm{OBS}}-\mathrm{T}_{\mathrm{ECM}}\right)$ and $68 \%$ fractiles of the absolute biases are shown for inhibited wave activity for the winter 1999/2000 in the first 6 rows. The numbers of points are given in the parentheses. From $26-11 \mathrm{hPa}$ the number of ECMWF layers increases, leading to a larger number of points even though less radiosondes reach this height. The median and $68 \%$ fractile are small except for above $26 \mathrm{hPa}$, where both ECMWF and radiosonde errors become larger. The largest radiation corrections occur during daylight, so it is no surprise that the $68 \%$ fractile decreases for night time data as seen in row 2 of the table. However, the median is almost unchanged.

One problem with the comparison to radiosonde temperatures is that they are assimilated into the ECMWF model together with e.g. satellite data. Therefore the ECMWF first guess, which is the 6-12 hour forecast from the previous analysis, has also been used. The first guess is independent from individual radiosonde data, but a general bias of all Vaisala radiosondes could in principle be transferred to the ECMWF analyses. There is no evidence, however, that such a bias should exist as indicated by the good agreement with the results mentioned above. The weakness of the first guess field is of course that it contains forecast errors. In data sparse regions the quality of the analyses might be reduced to one comparable to that of the first guess field. This might e.g. be the case at high latitudes for the first two winters, since less AMSU data were used in the assimilation before 22 January 2002.

In row 3 the differences to the first guess field are shown. There is a substantial increase in the median of the first guess compared to the analyses above $26 \mathrm{hPa}$. Thus the ECMWF model has a cold bias, which can partially explain the positive median for the analyses above $26 \mathrm{hPa}$. Other explanations include problems with the radiosonde temperatures due to a possible use of V86 radiations corrections for some of the radiosonde stations or a reduction of the ventilation of the temperature sensor as suggested by Luers and Eskeridge (1998). To get a feeling for the variability during the winter the February-March median for the analyses is shown in row 4 , and it is evident that only minor differences occur.

In row 5 the results for temperatures below $\mathrm{T}_{\mathrm{NAT}}$ are shown. Knudsen (1996) found a substantial warm bias of the ECMWF temperatures in February and March 1996 below $\mathrm{T}_{\mathrm{NAT}}$ from $125-25 \mathrm{hPa}$. The results from this study show that this bias almost vanished in 1999/2000, but as we shall see below, a substantial cold bias occurred in 2002/2003. The results for temperatures below $\mathrm{T}_{\mathrm{ICE}}+2.5 \mathrm{~K}$ in row 6 indicate a warm bias of such low ECMWF temperatures at $30 \mathrm{hPa}$. To get a fair statistic one must select for occasions where either observed or modelled or both temperatures are below the given threshold temperature (Manney et al., 1996).

ECMWF temperatures have been compared to completely independent observations on long- duration balloons. The results in row 4 agree well with the results of Pommereau et al. (2002) and Knudsen et al. (2002) for a flight from 18
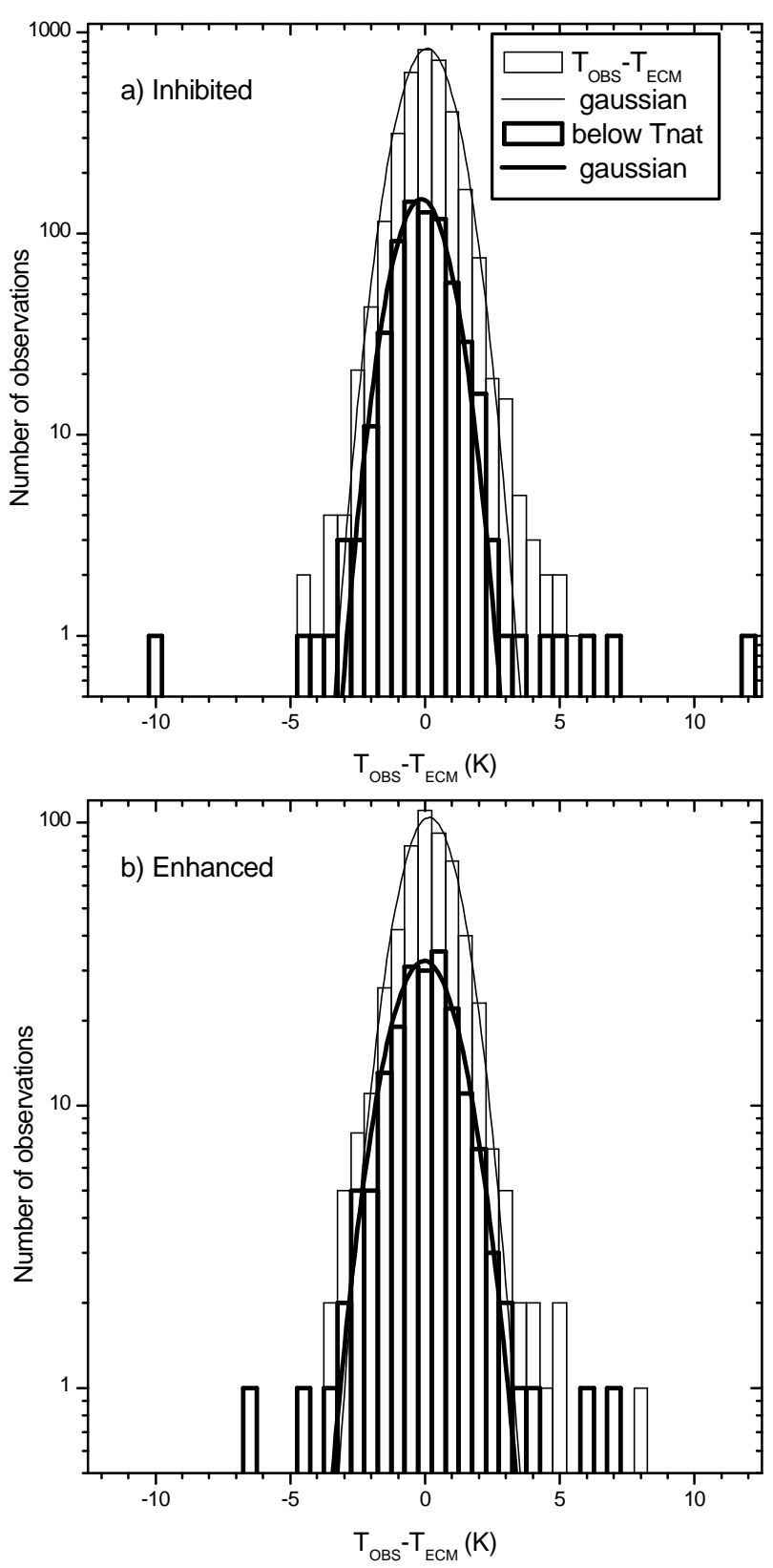

Fig. 1. Histogram of the 1999/2000 temperature biases for inhibited (a) and enhanced (b) wave activity. The histograms for temperatures below $\mathrm{T}_{\mathrm{NAT}}$ are shown in bold.

February-6 March 2000. Below $30 \mathrm{hPa}$ they get a bias and standard deviation of 0.49 and $0.91 \mathrm{~K}$, respectively, at temperatures mostly above $\mathrm{T}_{\mathrm{NAT}}$. Their larger standard deviations could be due to the use of non-layer averages, and their larger biases (by $\sim 0.25 \mathrm{~K}$ ) might be caused by a lower accuracy of the temperature sensors. Hertzog et al. (2003) used long-duration balloon temperatures above $\mathrm{T}_{\mathrm{NAT}}$ in the 2001/2002 winter vortex around $70 \mathrm{hPa}$ to find a cold bias of ECMWF temperatures of $0.3 \mathrm{~K}$ with a standard deviation of 
Table 2. Median temperature biases $\left(\mathrm{T}_{\mathrm{OBS}}-\mathrm{T}_{\mathrm{ECM}}\right)$ and $68 \%$ fractiles $(\mathrm{K})$

\begin{tabular}{lrrrr}
\hline Layer (hPa) & $105-61$ & $61-40$ & $40-26$ & $26-11$ \\
\hline 99/00: & & & & \\
1. analyses & $0.08 \pm 0.55(3534)$ & $0.16 \pm 0.69(3547)$ & $0.08 \pm 0.81(3371)$ & $0.60 \pm 1.16(6397)$ \\
2. night time & $0.06 \pm 0.54(2027)$ & $0.11 \pm 0.64(2113)$ & $-0.01 \pm 0.76(1804)$ & $0.58 \pm 1.08(3312)$ \\
3. first guess & $0.06 \pm 0.81(3615)$ & $0.06 \pm 0.98(3564)$ & $0.05 \pm 1.19(3314)$ & $0.91 \pm 1.66(6368)$ \\
4. Feb-Mar & $0.09 \pm 0.55(2076)$ & $0.24 \pm 0.68(1628)$ & $0.25 \pm 0.81(1617)$ & $0.61 \pm 1.20(2991)$ \\
5. T $<\mathrm{T}_{\mathrm{NAT}}$ & $0.04 \pm 0.59(671)$ & $0.26 \pm 0.69(866)$ & $-0.14 \pm 0.87(647)$ & $0.54 \pm 1.17(409)$ \\
6. T<T $\mathrm{T}$ ICE $+2.5 \mathrm{~K}$ & $0.79 \pm 0.39(6)$ & $0.11 \pm 0.84(60)$ & $-0.65 \pm 0.76(66)$ & $0.48 \pm 1.21(43)$ \\
02/03: & & & & \\
7. analyses & $0.19 \pm 0.62(2309)$ & $0.25 \pm 0.78(3169)$ & $0.68 \pm 0.89(3663)$ & $1.05 \pm 1.17(7003)$ \\
8. first guess & $0.23 \pm 0.76(2292)$ & $0.30 \pm 0.94(3102)$ & $0.83 \pm 1.13(3600)$ & $1.04 \pm 1.48(7056)$ \\
96/97,ERA40: & & & & \\
9. analyses & $-0.18 \pm 0.52(2267)$ & $-0.25 \pm 0.61(2036)$ & $-0.03 \pm 0.66(1799)$ & $-0.21 \pm 0.91(3017)$ \\
10. first guess & $-0.38 \pm 1.00(2213)$ & $-0.44 \pm 1.11(1965)$ & $0.40 \pm 1.37(1799)$ & $-0.66 \pm 2.00(3068)$ \\
\hline
\end{tabular}

$0.8 \mathrm{~K}$ in good agreement with the results for the 1999/2000 winter shown here. Their standard deviations agree better with the standard deviations of the first guess field (row 3 in Table 2), which may be a more appropriate comparison.

In rows 7-10 the results for the other two winters are given. Note that in the winter 1996/1997 the number of points is smaller because the vortex formed quite late. In $2002 / 2003$ there is a substantial bias, but a good agreement between the first guess and the analyses, whereas the opposite is the case in the 1996/1997 ERA40 reanalyses.

Figure 2 shows the ECMWF temperature bias during night time for all inhibited radiosondes with at least 10 observations. Some of the westernmost Canadian radiosonde stations use the VIZ type radiosondes, which can lead to large discrepancies if uncorrected. However, temperatures below $\mathrm{T}_{\mathrm{NAT}}$ are very rare at these stations. In 1996/1997 there is (erroneously) a negative (warm) bias over the Canadian stations, which could be related to their use of the Vaisala V93 radiation correction scheme. In the winter 2002/2003 there is a general positive (cold) bias, which is also present for the more accurate occasional RS90 radiosoundings. This is the only plot where Russian radiosondes and radiosondes outside the vortex have been included. The Russian sondes are included because they give an independent check on the ECMWF temperatures. The large biases over Russia in 2002/2003 may be evidence for a deteriorating Russian radiosonde network.

The size of the stationary anomalies found by Bowman et al. (1998) and Wagner and Bowman (2000) are not seen in the ECMWF biases. In the operational ECMWF data from 1994/1995 there are indeed signs of such large anomalies at $30 \mathrm{hPa}$ (Knudsen et al., 1996). These stationary anomalies could be caused by different radiosonde types (Lait, 2002). The reason for the small ECMWF anomalies might be the radiosonde bias correction scheme implemented at ECMWF: For 4 solar zenith angle intervals the radiosonde temperatures are corrected for the biases with respect to the first guess field for the preceding year (Onogi, 2000).

\subsection{Accuracy of the PSC extent in the analyses}

Figure 3 shows the percentage increase in the extent of radiosonde temperatures (without vertical averaging) relative to the ECMWF extent in $2 \mathrm{~K}$ wide temperature bins. Only data for inhibited wave activity with both accumulated radiosonde and ECMWF extents larger than $4 \mathrm{~km}$ in the vertical are plotted. Generally, there is an increase in the extent towards lower temperatures, but note that the errors also increase towards lower temperatures because of the decreasing amounts of data. The increased extent of frost point temperatures is not nearly as large as extrapolated from MO analyses in 1994/1995 at the $475 \mathrm{~K}$ isentropic level (Pullen and Jones, 1997). Below $26 \mathrm{hPa}$ ( $40 \mathrm{hPa}$ in 2002/2003) the extent of temperatures below $\mathrm{T}_{\mathrm{NAT}}$ (filled symbols at $\mathrm{T}-\mathrm{T}_{\mathrm{ICE}} \sim 7 \mathrm{~K}$ ) are within $10 \%$ of the extent based on radiosondes. In the first guess fields the extent below $26 \mathrm{hPa}$ is generally within $20 \%$. Not surprisingly the largest discrepancies occurs above $26 \mathrm{hPa}$, where ECMWF fields always overestimate the extent of PSCs on average. Manney et al. (2003) found very large discrepancies between PSC areas calculated with six different meteorological analyses in the winters 1995/1996 and 1999/2000. Compared to radiosonde observations the ECMWF PSC areas have much smaller discrepancies in 1999/2000, but in 2002/2003 comparable discrepancies are found at $30 \mathrm{hPa}$. In Fig. 4 the vertical extent (summed over all radiosondes) from $105-11 \mathrm{hPa}$ of temperatures below $\mathrm{T}_{\mathrm{ICE}}$ and $\mathrm{T}_{\mathrm{ICE}}+2.5 \mathrm{~K}$ are shown for ECMWF, radiosonde layer mean and the exact radiosonde temperatures for four winters. Both instances of inhibited and non-inhibited wave activity are used here. In the winters 1995/1996, 1996/1997, and 1999/2000 the radiosonde layer mean temperatures lead to a larger extent of low temperatures than ECMWF. This is partially due to lee-waves. The hatched regions tentatively 
a) $96 / 97$

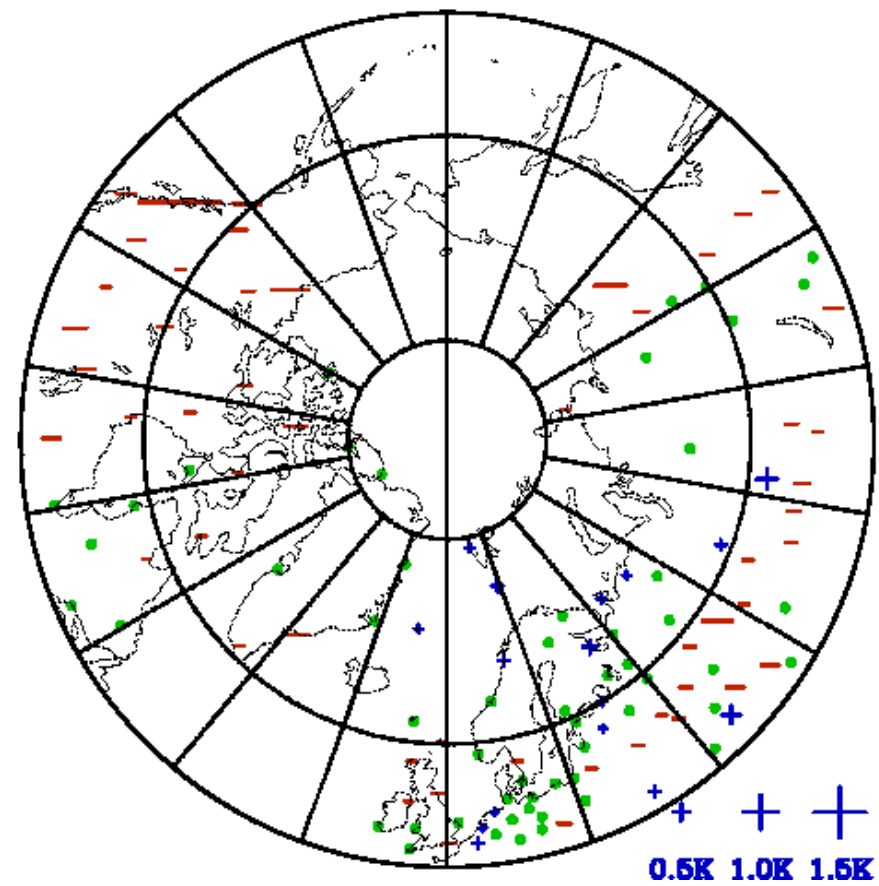

b) $99 / 00$

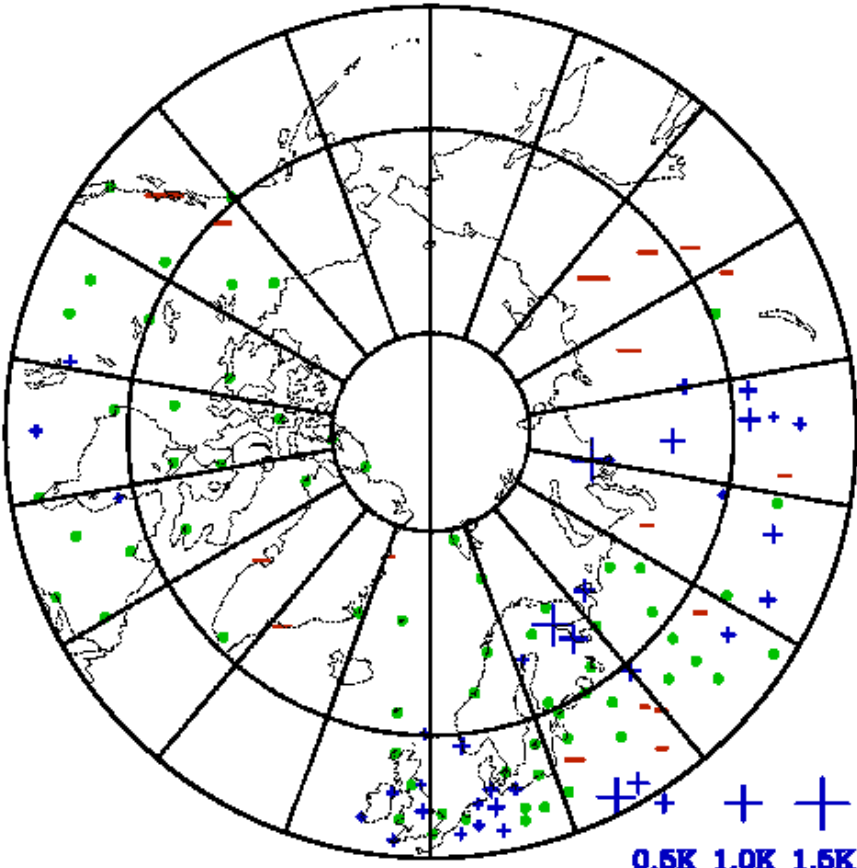

c) $02 / 03$

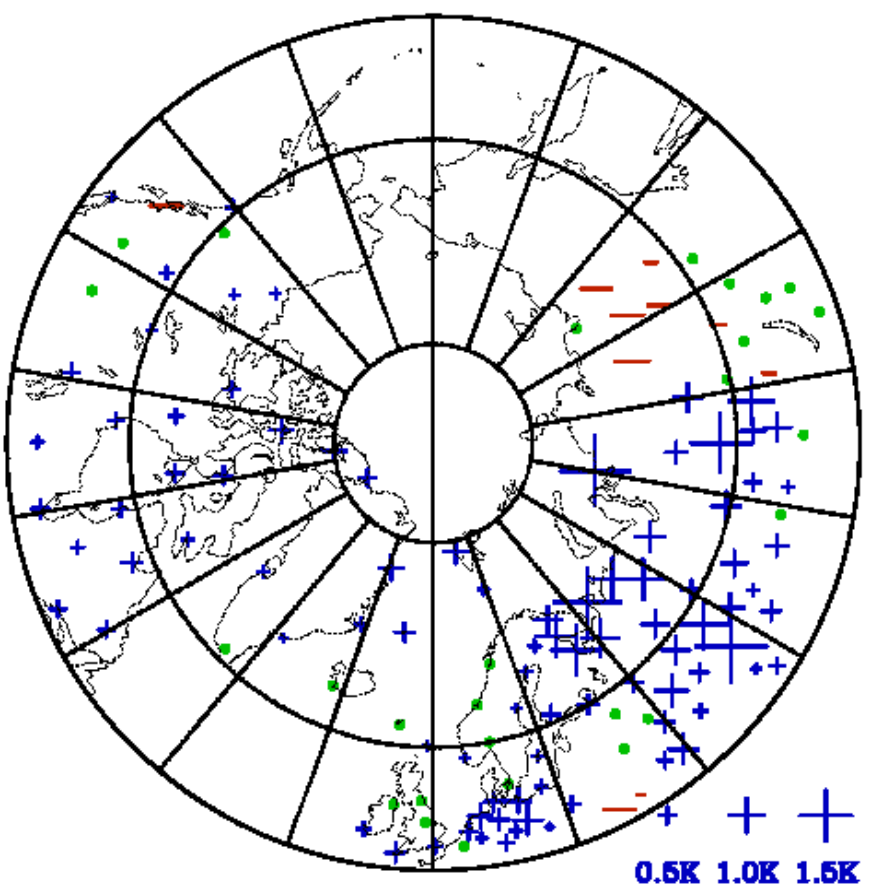

Fig. 2. $30 \mathrm{hPa}$ night time temperature biases $\left(\mathrm{T}_{\mathrm{OBS}}-\mathrm{T}_{\mathrm{ECM}}\right.$ ) north of $50^{\circ} \mathrm{N}$ in the winters $96 / 97$ (ERA40), 99/00, and 02/03. Red minuses indicate a warm bias of ECMWF relative to the radiosondes, whereas blue plusses indicate a cold bias. These follow the scale in the legend, whereas green dots indicate biases of magnitude less than $0.2 \mathrm{~K}$. Latitude circles are $50^{\circ}, 60^{\circ}$, and $80^{\circ} \mathrm{N}$ and the Greenwich meridian is at the bottom. The Russian sondes have not been used in the remainder of the paper. 


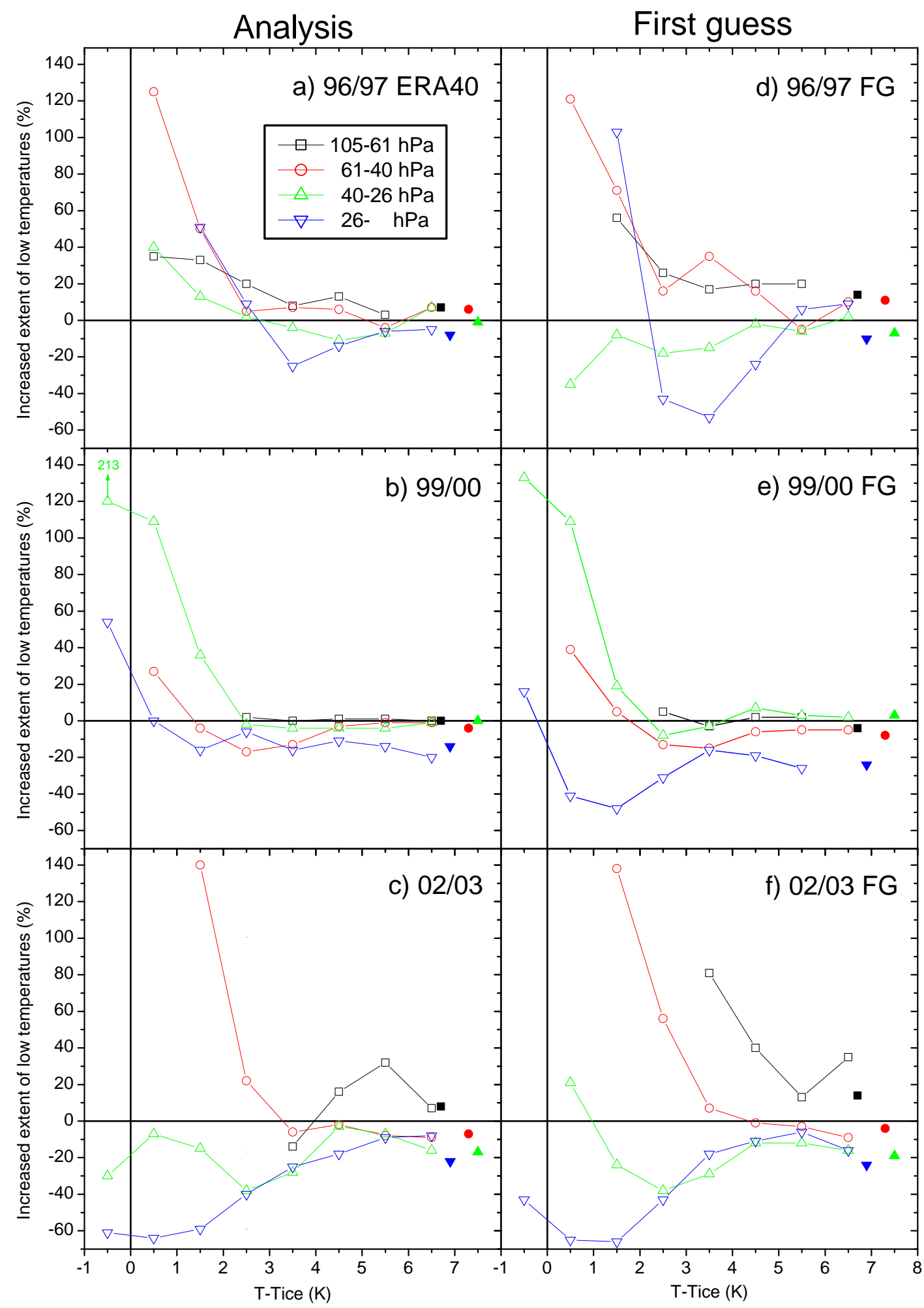

Fig. 3. Percentage increase in the extent of temperatures within $2 \mathrm{~K}$ wide bins when using radiosonde temperatures compared to when using ECMWF temperatures. Filled symbols show the increase for all temperatures below $\mathrm{T}_{\mathrm{NAT}}$. 
indicate the influence of lee-waves as described in appendix A. In the winter 2002/2003 the ECMWF temperatures have a substantial cold bias. In this winter no attempt to quantify the role of lee-waves below the frost point was made due to the uncertainties being too large. The largest effect of lee-waves is seen below the frost point, whereas for all temperatures below $\mathrm{T}_{\mathrm{NAT}}$ lee-waves have hardly any effect (not shown). The extent of the low temperatures is always larger for the exact radiosonde temperatures than for the layer averaged temperatures because such low temperatures are more likely to occur at the temperature minimum. Small-scale temperature variations, which ECMWF does not catch, thus substantially increase the extent of temperatures close to the frost point. Some of these fluctuations are due to lee-waves. The extreme coldness in the winter 1995/1996 might explain why the fraction of frost point temperatures explained by lee-waves is smaller that year. It might be that the use of high- resolution radiosonde data would further increase the extent of these low temperatures in the observations. In a warm winter with small extents of temperatures below $\mathrm{T}_{\mathrm{NAT}}$ ECMWF would probably likewise substantially underestimate these extents.

Dörnbrack and Leutbecher (2001) have shown that mountain waves enhance the potential for ice formation from 1980-1999 over Scandinavia in January by more than a factor of two. Scandinavia, however, is not the place where temperatures below $\mathrm{T}_{\mathrm{NAT}}$ most frequently occur (Pawson et al., 1995). Our study shows a much smaller effect of mountain waves on the ice formation potential in agreement with Knudsen et al. (2002) and Hertzog et al. (2002). This may be explained by a bias towards mountainous regions in their results. Another explanation may be the large differences between the methods used. Especially the use of four relatively cold winters in this study might influence the results, because in a warm winter synoptic temperatures may not reach the frostpoint. A complicating factor is that the ECMWF model itself does simulate some mountain waves, particularly in the $2002 / 2003$ winter, when the horizontal resolution was highest.

\subsection{Temperature corrections}

The half-filled symbols in Fig. 5 indicate the median bias $\left(\mathrm{T}_{\mathrm{OBS}}-\mathrm{T}_{\mathrm{ECM}}\right)$ for all temperatures below $\mathrm{T}_{\mathrm{NAT}}$ and below $\mathrm{T}_{\mathrm{ICE}}+2.5 \mathrm{~K}$. Points based on fewer than 5 observations are not plotted, whereas points based on 5-10 observations are only plotted if the $68 \%$ fractile of the absolute biases are less than $1.5 \mathrm{~K}$. Figure 5 is more or less a reflection of Fig. 3. Similar to Fig. 3 the first guess biases generally have the same sign as the analysis biases, but are larger numerically. This indicates that systematic model errors play a role in the temperature biases of the analyses.

Other symbols in Fig. 5 show the temperature correction needed to be added to ECMWF temperatures to obtain the radiosonde PSC extent (without vertical averaging). This is a somewhat constructed quantity, which is not as robust against
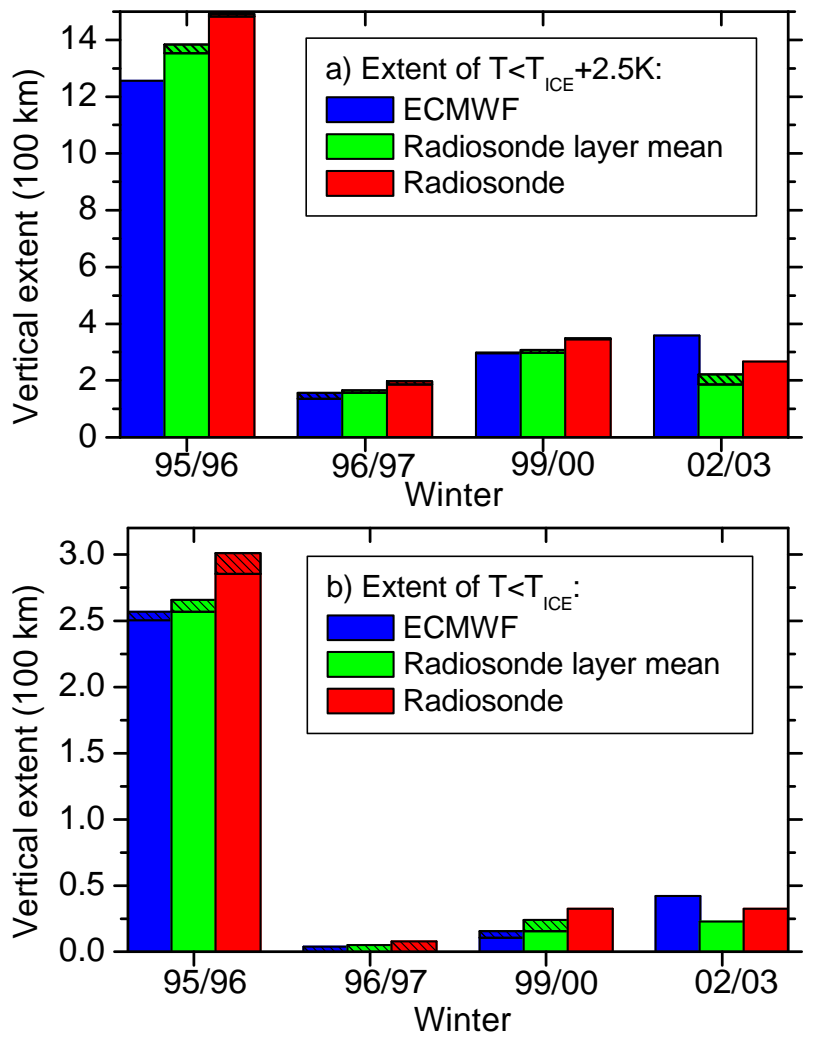

Fig. 4. Vertical extent (summed over all radiosondes) of temperatures below $\mathrm{T}_{\mathrm{ICE}}+2.5 \mathrm{~K}$ (a) and $\mathrm{T}_{\mathrm{ICE}}$ (b) from $105-11 \mathrm{hPa}$ for ECMWF (blue), radiosonde layer mean (green) and the exact radiosonde temperatures (red) for four winters. The hatched regions tentatively indicate the influence of lee-waves as described in the appendix.

radiosonde errors as the median. However, this correction is the one to apply to e.g. a chemical transport model to get the most realistic PSC extent on average through the winter. Programmes to apply these temperature corrections (from the regression lines) to ECMWF temperatures can be downloaded from ftp://ftp.dmi.dk/pub/Ozon/ecmwftcorrections/.

In the winters 1996/1997 and 1999/2000 the temperature corrections for the analyses are small, while they are somewhat larger for the first guess fields. This is particularly true in 1996/1997 and may be due to the use of a poorer model for ERA40. In the winter 2002/2003 the analysis corrections are larger, particularly above $40 \mathrm{hPa}$, but for the first guess fields the corrections are about the same. The general increase towards the frost point in Fig. 3 is reflected in Fig. 5 as a general decrease of the temperature corrections towards the frost point.

Figure 5 shows a substantial cold bias of ECMWF temperatures in the winter 2002/2003 from $11-40 \mathrm{hPa}$. It is difficult to point to a single cause of the large biases, but it may be connected to the assimilation of low-vertical-resolution satellite data, in which upper stratospheric biases can cause 


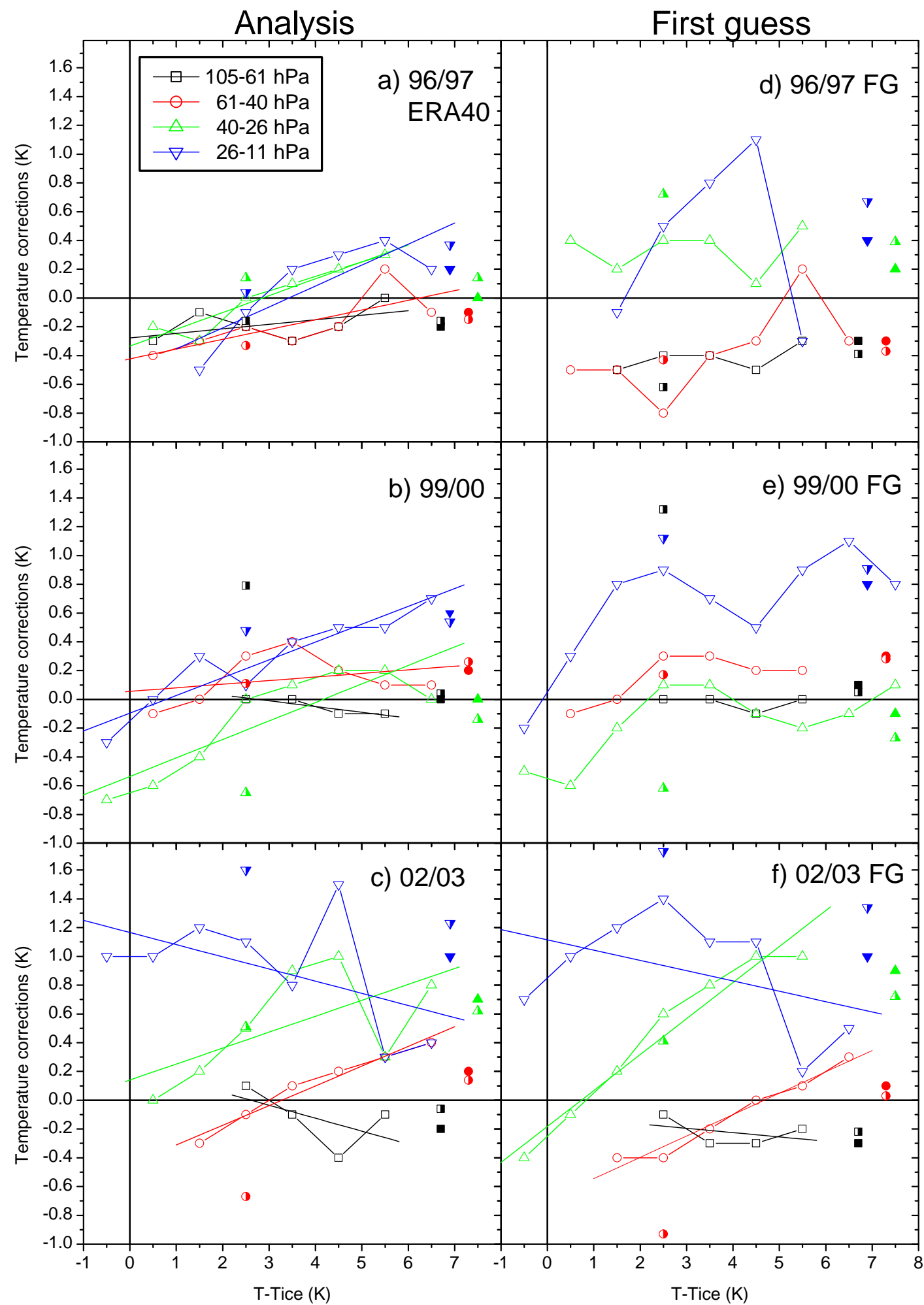

Fig. 5. Temperature corrections needed to be added to ECMWF temperatures to obtain the observed extent of temperatures in $2 \mathrm{~K}$ wide temperature bins in winter for the analyses in 1996/97 (ERA40) (a), 1999/2000 (b), and 2002/2003 (c) and for the first guess fields in 1996/97 (ERA40) (d), 1999/2000 (e), and 2002/2003 (f). Linear regression lines are also shown. The filled symbols show the corrections needed for all temperatures below $\mathrm{T}_{\mathrm{NAT}}$. Half-filled symbols shows the median bias for temperatures below $\mathrm{T}_{\mathrm{NAT}}$ and $\mathrm{T}_{\mathrm{ICE}}+2.5 \mathrm{~K}$. 
changes in the lower stratosphere. In the ERA-40 reanalyses similar problems occur over the poles from 1998 onwards. Radiosonde errors do increase at the top levels, but such a large systematic bias is unlikely, especially during night time. Due to the 4D variational data analysis with 12 hour assimilation window the first guess field is a 12 hour forecast of the previous analyses in the winter 2002/2003, whereas it is a $6 \mathrm{~h}$ forecast in the other winters. This should increase the forecast errors, but in fact the results for the first guess field is quite similar to the results for the analyses at least in the mean.

\section{Conclusions}

The accuracy of ECMWF (European Centre for MediumRange Weather Forecasts) temperatures have been investigated by comparison to radiosonde temperatures. One problem with this comparison is that the radiosonde temperatures are assimilated in the model. However, using the ECMWF first guess fields (i.e. the 6-12 hourly forecasts from the previous analyses), which are independent from the radiosonde data, gives comparable results. Below $26 \mathrm{hPa}$ ( $40 \mathrm{hPa}$ in 2002/2003) the extent of temperatures below $\mathrm{T}_{\mathrm{NAT}}$ are within $10 \%$ of the extent based on radiosondes. In the first guess fields the extent below $26 \mathrm{hPa}$ is generally within $20 \%$. Not surprisingly the largest discrepancies occurs above $26 \mathrm{hPa}$, where ECMWF fields always overestimate the extent of PSCs on average.

\section{Appendix: Effect of lee-waves}

It is not obvious how to define the effect of lee-waves on the PSC extents. The following definition is chosen: The vertical extent of temperatures below a given threshold for ECMWF, radiosonde and radiosonde mean layer temperatures is denoted $V_{e c}, V_{r}$, and $V_{r m}$. The extent of the inhibited data has added an " $i$ " in the subscript. The extent of the hatched (lee-wave caused) green part is defined as:

$V_{r m}-V_{r m i}\left(V_{e c} / V_{e c i}\right)$

If this quantity is larger than the green area by an extent, $\mathrm{x}$, then an extent, $\mathrm{x}$, of the blue area is hatched. Thus, the blue-hatched region shows how much smaller the PSC extent would be for the radiosonde layer mean data with only inhibited wave activity. This occurs when ECMWF has a cold bias compared to the radiosonde layer mean temperatures at the temperature threshold. The extent of the red-hatched region is defined as:

$V_{r}-V_{r i}\left(V_{r m} / V_{r m i}\right)$

In the case of 1997, where no temperatures below the frost point occur for inhibited wave activity, everything is hatched.

Acknowledgements. ECMWF is acknowledged for both their operational and reanalysis data. Adrian Simmons is thanked for valuable comments to the paper. Fruitful discussions with Andreas Stohl are gratefully acknowledged. Albert Hertzog and an anonymous referee are thanked for valuable comments. The study was funded by the CEC within the MAPSCORE project.

\section{References}

Bowman, K. P., Hoppel, K., and Swinbank, R.: Stationary anomalies in stratospheric meteorological data sets, Geophys. Res. Lett., 25, 2429-2432, 1998.

Buss, S.: Dynamical aspects of polar stratospheric cloud formation, denitrification and ozone loss, Ph.D. thesis, accepted, ETHZürich, 2003.

Davies, S., Chipperfield, M. P., Carslaw, K. S., et al.: Modeling the effect of denitrification on Arctic ozone depletion during winter 1999/2000, J. Geophys. Res., 107, 8322, 10.1029/2001JD000445, 2002.

Dörnbrack, A. and Leutbecher, M.: Relevance of mountain waves for the formation of polar stratospheric clouds over Scandinavia: A 20 year climatology, J. Geophys. Res., 106, 1583-1593, 2001.

Dörnbrack, A., T. Birner, A. Fix, H. Flentje, A. Meister, H. Schmid, E. V. Browell, and M. J. Mahoney, Evidence for inertia gravity waves forming polar stratospheric clouds over Scandinavia. JGR 107(D20), 8287, doi:10.1029/2001JD000452, 2002.

Hertzog, A., Vial, F., Dörnbrack, A., Eckermann, S. D., Knudsen, B. M., and Pommereau, J.-P.: In-situ observations of gravity waves and comparison with numerical simulations during SOLVE/THESEO 2000 campaign, J. Geophys. Res, 107, (D20), 8292, 10.1029/2001JD001025, 2002.

Hertzog, A., Basdevant, C., Vial, F., and Mechoso, C. R.: Some results on the accuracy of stratospheric analyses in the Northern Hemisphere inferred from long-duration Balloon flights, Q. J. R. Meteorol. Soc., accepted, 2003.

Knudsen, B. M.: Accuracy of arctic stratospheric temperature analyses and the implications for the prediction of polar stratospheric clouds, Geophys. Res. Lett., 23, 3747-3750, 1996.

Knudsen, B. M., Pommereau, J.-P., Garnier, A., Nunes-Pinharanda, M., Denis, L., Newman, P., Letrenne, G., and Durand, M. Accuracy of Analyzed Stratospheric Temperatures in the Winter Arctic Vortex from Infra Red Montgolfier Long Duration Balloon Flights, Part II: Results, J. Geophys. Res., 107(D20), 10.1029/2001JD001329, 2002.

Lait, L. R.: An alternative form for potential vorticity, J. Atm. Sci., 51, 1754-1759, 1994.

Lait, L. R.: Systematic differences between radiosonde instruments, Geophys. Res. Lett., 29(10), 10.1029/2001GL014337, 2002.

Luers, J. K. and Eskeridge, R. E.: Use of radiosonde temperature data in climate studies, J. Clim., 11, 1002-1019, 1998.

Manney, G. L., Swinbank, R., Massie, S. T., et al.: Comparison of U.K. Meteorological Office and U.S. National Meteorological Center stratospheric analyses during northern and southern winter, J. Geophys. Res., 101, 10311-10 334, 1996.

Manney, G. L., Sabutis, J. L., Pawson, S., et al.: Lower stratospheric temperature differences between meteorological analyses in two cold Arctic winters and their impact on polar processing studies, J. Geophys. Res., 108, 11.1029/200JD001149, 2003.

Onogi, K.: The long-term performance of the radiosonde observing system to be used in ERA-40, ERA-40 project report series No. 2, Available from ECMWF, Shinfield Park, 2000. 
Pawson, S., Naujokat, B., and Labitzke, K.: On the PSC formation potential of the northern stratosphere, J. Geophys. Res., 100, 23 215-23 225, 1995.

Pommereau, J.-P., Garnier, A., Knudsen, B. M., et al.: Accuracy of Analyzed Stratospheric Temperatures in the Winter Arctic Vortex from Infra Red Montgolfier Long Duration Balloon Flights, Part I: Measurements, J. Geophys. Res., 107 (D20), 10.1029/2001JD001379, 2002.

Pullen, S. and Jones, R. L.: Accuracy of temperatures from UKMO analyses of 1994/95 in the arctic winter stratosphere, Geophys. Res. Lett., 24, 845-848, 1997.

Rabier, F., Jrvinen, H., Klinker, E., Mahfouf, J.-F., and Simmons, A.: The ECMWF operational implementation of four dimensional variation assimilation, I: Experimental results with simplified physics, Q. J. R. Meteorol. Soc., 126, 1143-1170, 2000.
Schiller, C., Bauer, R., Cairo, F., et al.: Dehydration in the Arctic stratosphere during the SOLVE/THESEO-2000 campaigns, J. Geophys. Res., 107 (D20), 8293, doi:10.1029/2001JD000463, 2002.

Simmons, A. J., Untch, A., Jacob, C., Kållberg, P., and Undén, P.: Stratospheric water vapour and tropical tropopause temperatures in ECMWF analyses and multi-year simulations, Q. J. R. Meteorol. Soc., 125, 353-386, 1999.

Simmons, A. J. and Gibson, J. K.: The ERA-40 project plan, ERA40 project report series No. 1, Available from ECMWF, Shinfield Park, Reading, 2000.

Wagner, R. E. and Bowman, K. P.: Wavebreaking and mixing in the Nortern Hemisphere summer stratosphere, J. Geophys. Res., 105, 24 799-24 807, 2000.

Whiteway, J. A.: Enhanced and inhibited Gravity Wave Spectra, J. Atm. Sci., 56, 1344-1351, 1999

WMO: Report by the rapporteur on radiosonde compatibility monitoring, Rep. 72, pp. 100, Geneva, 1998. 